\title{
Kajian Paparan dan Risiko 3-MCPDE dan GE dari Produk Formula pada Bayi Usia 0-12 Bulan di Indonesia secara Probabilistik
}

\author{
Exposures and Risk Assessment of 3-MCPDE and GE in Formula Products \\ to Infant Aged 0-12 Months in Indonesia with Probabilistic Approach
}

\author{
Wiwi Hartuti ${ }^{1,2)}$, Nuri Andarwulan ${ }^{2,3)^{*}}$, dan Puspo Edi Giriwono ${ }^{2,3)}$ \\ ${ }^{1)}$ Departemen Ilmu dan Teknologi Pangan, Fakultas Teknologi Pertanian, Institut Pertanian Bogor, Bogor \\ ${ }^{2)}$ Badan Pengawas Obat dan Makanan Republik Indonesia \\ ${ }^{3)}$ South East Asian Food and Agricultural Sciences and Technology Center, Institut Pertanian Bogor, Bogor
}

\begin{abstract}
The 3-monochloropropane-1.2-diol ester (3-MCPDE) and glycidyl ester (GE) are chemical contaminants detected in vegetable oils and food products containing vegetable oils including formula products. This study aimed to assess the exposure and risk of 3-MCPDE and GE from infants formula products in Indonesia. Prediction of 3-MCPDE and GE levels of formula products was carried out probabilistically using data levels of 3-MCPDE and GE vegetable oil. Estimated daily intake (EDI) of 3-MCPDE and GE of formula products were obtained by multiplying the predicted data by consumption data while risk assessment is done by comparing EDI value with toxicology reference value. The predicted values of 3-MCPDE and GE levels of formula products ranged from $213.60-285.65$ and $772.89-922.73 \mu \mathrm{g} / \mathrm{kg}$. The exposure value of 3-MCPDE and GE of formula products based on Individual Food Consumption Survey (IFCS) was 1.53-2.40 and 5.54$7.11 \mu \mathrm{g} / \mathrm{kgbw} / \mathrm{day}$, while based on serving consumption was 3.31-6.68 and 10.88-21.62 $\mu \mathrm{g} / \mathrm{kgbw} / \mathrm{day}$. Results of risk assessment indicated that 3-MCPDE was above 100\% (health risk) in exception that of the age group 6-12 months based on IFCS with a value of 76.98-84.34\%, the average GE with the T25 margin of exposure (MoE) was 1838-471 which was below 25.000. EFSA defined MoE T25 at 25.000 as GE's low risk to health.
\end{abstract}

Keywords: 3-MCPDE, formula products, GE, risk assessment, vegetables oil

\begin{abstract}
Abstrak. Senyawa 3-monochloropropane-1.2-diol ester (3-MCPDE) dan glycidyl ester (GE) merupakan kontaminan kimia yang terdeteksi pada minyak nabati dan produk pangan yang mengandung minyak nabati termasuk produk formula. Penelitian ini bertujuan untuk melakukan kajian paparan dan risiko 3-MCPDE dan GE dari produk formula pada bayi di Indonesia. Penentuan prediksi kadar 3-MCPDE dan GE dari produk formula dilakukan secara probabilistik berdasarkan kadar 3-MCPDE dan GE minyak nabati. Nilai paparan atau estimated daily intake (EDI) dari 3MCPDE dan GE dari produk formula diperoleh dengan mengalikan data prediksi kadar dengan data konsumsi, sedangkan penilaian risiko dilakukan dengan membandingkan nilai EDI dengan nilai referensi toksikologi. Nilai prediksi kadar 3-MCPDE dan GE dari produk formula berkisar antara 213.60-285.65 dan 772.89-922.73 $\mu \mathrm{g} / \mathrm{kg}$. Nilai rata-rata paparan 3-MCPDE dan GE dari produk formula berdasarkan konsumsi SKMI adalah 1.53-2.40 dan 5.54-7.11 $\mu \mathrm{g} / \mathrm{kgBB} / \mathrm{hari}$, sedangkan berdasarkan konsumsi takaran saji adalah 3.31-6.68 dan 10.88-21.62 $\mu \mathrm{g} / \mathrm{kgBB} / \mathrm{hari}$. Hasil penilaian risiko 3-MCPDE berada di atas 100\% (berisiko terhadap kesehatan) kecuali pada kelompok usia 6-12 bulan berdasarkan konsumsi SKMI dengan nilai 76.98-84.34\%. Penilaian risiko GE dengan pendekatan margin of exposure (MoE) T25 didapatkan nilai rata-rata MoE adalah 1838-471. Nilai rata-rata MoE T25 ini masih berada di bawah 25.000. EFSA (2016) menetapkan MoE T25 225.000 sebagai batas risiko rendah GE terhadap kesehatan.
\end{abstract}

Kata Kunci: 3-MCPDE, GE, kajian paparan, minyak nabati, produk formula

Aplikasi Praktis. Penelitian ini memberikan informasi tentang tingkat risiko akibat paparan 3-
MCPDE dan GE dari produk formula pada bayi usia 0-12 bulan di Indonesia. Hasil penelitian
menunjukkan paparan 3-MCPDE dan GE dari produk formula berisiko terhadap kesehatan kecuali
paparan 3-MCPDE pada kelompok usia 6-12 bulan dengan menggunakan data konsumsi SKMI.

\section{PENDAHULUAN}

Air susu ibu (ASI) merupakan asupan terbaik untuk bayi dan berperan sebagai pangan ideal yang penting

Korespondensi: andarwulan@apps.ipb.ac.id untuk pemenuhan zat gizi bayi (Luron et al. 2010; Blanchard et al. 2013). Kemenkes 2018 pada laporan Riskesdas Tahun 2018 pencapaian ASI ekslusif di Indonesia hanya sebesar 37.3\%. Hal ini menunjukkan masih terdapat keterbatasan untuk memperoleh ASI. Air susu ibu (ASI) adalah matriks kompleks dengan komposisi 
umum $87 \%$ air, $3.8 \%$ lemak, $1.0 \%$ protein, dan $7 \%$ laktosa. Kandungan lemak ASI berperan dalam menyumbang 40-50\% kalori untuk bayi dan menyediakan asam lemak esensial yang dibutuhkan tubuh seperti asam lemak dokosaheksanoat (DHA) dan asam lemak arakidonat (AA) (Mehrotra et al. 2018; Blanchard et al. 2013; Martin et al. 2016). Produk formula dalam hal ini formula bayi (usia 0-6 bulan) dan formula lanjutan (usia 6-12 bulan) dapat menjadi produk alternatif untuk mengganti ketersediaan ASI dan diharapkan memiliki kemiripan kandungan nutrisi baik secara makro dan mikro.

Komposisi produk formula secara umum terdiri dari susu sapi atau susu kedelai yang telah diproses lebih lanjut dengan penambahan komponen nutrisi lain agar memiliki spesifikasi zat gizi yang sesuai dengan kebutuhan bayi (Martin et al. 2016). Minyak nabati merupakan salah satu komponen penting pada produk formula yang digunakan untuk menyusun komposisi kandungan lemak agar dapat menyerupai kandungan lemak pada ASI (Delplanque et al. 2015). Namun, sebagian besar minyak nabati yang ditambahkan telah melalui proses pemurnian dan menjadi masalah keamanan pangan karena kemungkinan adanya cemaran kimia seperti 3MCPD (3-mono-chloropropane-1.2-diol) ester dan glycidyl ester (GE) (Pudel et al. 2016; Arisseto et al. 2017).

Senyawa 3-MCPDE dan glycidyl esters (GE) sejak tahun 2004 telah teridentifikasi sebagai cemaran kimia pada berbagai produk pangan dan bahan pangan (EFSA 2016), contohnya pada minyak kelapa sawit. Kadar 3MCPDE dan GE minyak kelapa sawit hasil proses pemurnian berada pada kisaran yang cukup tinggi yaitu 1510-7230 dan 330-10520 $\mu \mathrm{g} / \mathrm{kg}$ (MacMahon et al. 2013). Kadar 3-MCPDE pada produk formula pertama kali dilaporkan oleh Zelinkova et al. (2009) dengan nilai berkisar antara 62 sampai $588 \mu \mathrm{g} / \mathrm{kg}$. Wohrlin et al. 2015 melaporkan kadar 3-MCPDE dan GE pada 70 sampel formula bayi di Jerman yaitu sebesar 148-650 $\mu \mathrm{g} / \mathrm{kg}$ dan 213-320 $\mu \mathrm{g} / \mathrm{kg}$. 3-MCPDE dan GE terhidrolisis secara sempurna $(100 \%)$ di dalam saluran pencernaan menjadi bentuk bebasnya yaitu 3-MCPD dan glisidol (EFSA 2016). International Agency for Research on Cancer (IARC) mengelompokkan senyawa 3-MCPD sebagai senyawa yang berpotensi menyebabkan kanker bagi manusia (kelompok 2B) dan glisidol kelompok 2A (genotoksik dan karsinogenik) (IARC 2012).

Konsumsi produk formula yang tinggi di Indonesia dapat menimbulkan risiko kesehatan apabila tercemar oleh senyawa kimia seperti 3-MCPDE dan GE. Oleh karena itu perlu dilakukan kajian paparan agar dapat diketahui tingkat risiko kesehatan akibat mengonsumsi produk formula. Penelitian ini bertujuan untuk (1) mendapatkan data prediksi kadar 3-MCPDE dan GE dari produk formula, (2) mendapatkan data paparan 3MCPDE dan GE dari produk formula serta (3) menentukan tingkat risiko 3-MCPDE dan GE dari produk formula dengan cara membandingkan nilai paparan dengan nilai referensi toksikologi.

\section{BAHAN DAN METODE}

\section{Bahan}

Bahan yang digunakan adalah (1) data konsumsi produk formula dan berat badan bayi berdasarkan laporan SKMI Tahun 2014 (Kemenkes 2014), (2) data takaran saji yang terdapat pada label kemasan, (3) data kadar lemak pada label produk formula, (4) data kadar lemak dan jenis minyak nabati pada produk formula (Novian 2019), (5) data kadar 3-MCPDE dan GE minyak kelapa sawit (BPOM 2018), (6) data kadar 3MCPDE dan GE minyak kedelai, kelapa dan biji bunga matahari dengan nomor izin edar makanan dalam negeri (MD) dan makanan luar negeri (ML) hasil sampling dan dilanjutkan pengujian di laboratorium BPMB Kementerian Perdagangan. Alat yang digunakan pada penelitian ini adalah komputer dengan aplikasi @ RISK 7.6.

\section{Penentuan prediksi kadar 3-MCPDE dan GE dari produk formula}

Penentuan prediksi kadar 3-MCPDE dan GE pada produk formula dilakukan secara probabilistik menggunakan data kadar 3-MCPDE dan GE dari minyak nabati. Penghitungan sampel minyak nabati pada penelitian ini menggunakan metode Slovin (Ryan 2013) dan setiap sampel diambil masing-masing dua buah dengan batch yang berbeda. Data kadar 3-MCPDE dan GE minyak kelapa sawit didapatkan dari BPOM (2018) sebanyak 125 sampel, sedangkan sampel untuk minyak kedelai (6 sampel), minyak kelapa (7 sampel) dan minyak biji bunga matahari (7 sampel) dilakukan pengujian pada laboratorium BPMB (terakreditasi ISO 17025) Kementerian Perdagangan. Pengujian dilakukan menggunakan metode standar AOCS Cd 29a-13 dengan instrumen GCMS TQ8030 Triple Quadrupole Mass Spectrometer (Shimadzu, Japan) dan kolom Elite-5MS, $30 \mathrm{~m} \times 0.25 \mathrm{~mm} \times 0.25 \mu \mathrm{m}$. Standar analisis rac 1,2-bispalmitoyl-3-chloropropanediol (3-MCPD ester) dan rac 1.2-bis-palmitoyl-3-chloropropanediol-D5 (3-MCPD-D5 ester) serta internal standar glycidyl palmitate (Gly-P) dan glycidyl oleate-D5 (Gly-O-D5) didapatkan dari Toronto Research Chemicals Inc.

Penghitungan prediksi kadar 3-MCPDE dan GE dari produk formula menggunakan data kadar 3-MCPDE dan GE minyak nabati dengan pemodelan matematika secara sederhana. Pemodelan ini terdiri dari komposisi (\%) minyak nabati yang digunakan sebagai bahan penyusun lemak pada produk formula, kadar (\%) lemak yang terdapat pada produk formula dan kadar 3-MCPDE dan GE $(\mu \mathrm{g} / \mathrm{kg})$ pada minyak nabati. Contoh perhitungan prediksi kadar 3-MCPDE dan GE dari produk formula dapat dilihat pada Tabel 1. Komposisi minyak nabati dan kadar lemak yang digunakan pada penelitian ini diperoleh dari hasil penelitian Novian (2019) dengan menggunakan sampel produk formula berbasis susu sapi. Kadar lemak pada produk formula juga didapatkan dari hasil sampling dan pencatatan kadar lemak yang terdapat pada label kemasan produk formula. 
Tabel 1. Prediksi kadar rata-rata 3-MCPDE (lower bound) pada formula bayi menggunakan aplikasi @RISK 7.6

\begin{tabular}{lccc}
\hline $\begin{array}{l}\text { Bahan } \\
\text { baku/ } \\
\text { minyak } \\
\text { nabati }\end{array}$ & $\begin{array}{c}\text { Komposisi } \\
\text { minyak nabati } \\
\text { dalam formula } \\
\text { bayi }(\%)\end{array}$ & $\begin{array}{c}\text { Kadar 3- } \\
\text { MCPDE dalam } \\
\text { minyak nabati } \\
(\mu \mathrm{g} / \mathbf{k g})\end{array}$ & $\begin{array}{c}\text { Kadar 3-MCPDE } \\
\text { dalam bahan } \\
\text { baku formula } \\
\text { bayi }(\boldsymbol{\mu g} / \mathbf{k g})\end{array}$ \\
\hline $\begin{array}{l}\text { Kelapa } \\
\text { sawit }\end{array}$ & 44.93 & 2003.70 & 900.26 \\
Kedelai & 19.84 & 188.05 & 37.31 \\
Kelapa & 14.76 & 573.13 & 84.59 \\
$\begin{array}{l}\text { Biji bunga } \\
\text { matahari }\end{array}$ & 21.58 & 287.63 & 62.07
\end{tabular}

Faktor yang Memberikan Kontribusi Peningkatan dan Penurunan Kadar 3-MCPDE dalam Proses Pengolahan Formula Bayi

$\begin{array}{lc}\text { Pencampuran } & 0 \\ \text { Penguapan } & 0 \\ \text { Pengeringan } & 0 \\ \text { Nilai total 3-MCPDE pada bahan baku }(\mu \mathrm{g} / \mathrm{kg}) & 1084.23 \\ \text { Persentase lemak dalam formula bayi }(\%) & 26.25 \\ \text { Prediksi kadar 3-MCPDE pada formula bayi } & 284.74\end{array}$

$(\mu \mathrm{g} / \mathrm{kg})$

Pengumpulan dan pengolahan data konsumsi dan berat badan bayi

Data konsumsi produk formula yang digunakan pada penelitian ini adalah data konsumsi SKMI tahun 2014 (Kemenkes 2014) dan konsumsi takaran saji. Data konsumsi SKMI didapatkan dengan mengajukan permintaan data ke Litbang Kementerian Kesehatan. Data yang diminta adalah data konsumsi formula bayi dan formula lanjutan serta berat badan bayi kelompok usia 0-6 dan 6-12 bulan. Data konsumsi takaran saji didapatkan dengan melakukan pencatatan takaran saji yang yang terdapat pada label kemasan produk formula. Sampel produk formula didapatkan dengan cara melakukan sampling menggunakan metode Slovin (Ryan 2013).

\section{Kajian paparan 3-MCPDE dan GE dari produk formula}

Nilai paparan atau EDI dihitung dengan mengalikan data prediksi kadar 3-MCPDE dan GE dengan data konsumsi produk formula, kemudian dibagi data berat badan. Penentuan nilai paparan ini dilakukan dengan mengasumsikan 3-MCPDE dan GE di dalam saluran pencernaan terhidrolisis secara sempurna (100\%) menjadi bentuk bebasnya yaitu 3-MCPD dan glisidol (EFSA 2016). Perhitungan dilakukan dengan menggunakan rumus sebagai berikut:

Paparan $(\mu \mathrm{g} / \mathrm{kg} \mathrm{bb} / \mathrm{hari})=$

$$
\frac{\sum \text { konsumsi }\left(\frac{\mathrm{g}}{\text { hari }}\right) \times \sum \text { kadar }\left(\frac{\mu \mathrm{g}}{\mathrm{kg}}\right)}{\text { berat badan }(\mathrm{kg})} \times \frac{1}{1000}
$$

\section{Penentuan tingkat risiko 3-MCPDE dan GE dari produk formula}

Tingkat risiko 3-MCPDE dilakukan dengan membandingkan nilai paparan atau (EDI) dengan nilai referensi toksikologi yaitu Tolerable Daily Intake (TDI) dari 3-MCPDE. Berikut persamaan untuk menghitung karakterisasi risiko paparan 3-MCPDE:

$$
\% \text { Risiko }=\frac{\text { nilai EDI }}{\text { nilai TDI }} \times 100
$$

Penentuan tingkat risiko GE dilakukan dengan pendekatan Margin of Exposure (MoE) T25 (EFSA 2016). Nilai T25 adalah dosis yang menyebabkan kemungkinan terjadinya kenaikan kejadian tumor (mesothelioma peritoneum) pada hewan percobaan (tikus jantan) sebanyak 25\% yaitu $10.2 \mathrm{mg} / \mathrm{kgBB} /$ hari. Perhitungan nilai MoE dilakukan dengan membagi nilai T25 dengan nilai paparan atau nilai EDI. Berikut persamaan untuk menghitung tingkat risiko GE menggunakan pendekatan MoE:

$$
\begin{aligned}
& \text { Margin of Exposure }= \\
& \qquad \frac{\text { Nilai T25 }\left(\frac{\mathrm{mg}}{\mathrm{kg}} \text { berat badan perhari }\right) \times 100}{\text { Nilai EDI }\left(\frac{\mu \mathrm{gg}}{\mathrm{kg}} \text { berat badan perhari }\right)}
\end{aligned}
$$

\section{Analisis data}

Analisis dan pengolahan data dilakukan secara probabilistik menggunakan simulasi Monte Carlo dengan aplikasi @RISK 7.6. Data pada penelitian ini disajikan dalam kisaran lower bound-upper bound, ratarata, median dan P95.

\section{HASIL DAN PEMBAHASAN}

Kadar lemak dalam produk formula dan jenis minyak nabati sebagai penyusun lemak

Komposisi ASI digunakan sebagai model untuk merancang komposisi produk formula (Mehrotra et al. 2018; Martin et al. 2016; Blanchard et al. 2013; Gianni et al. 2012). Sebagian besar produk formula yang tersedia di pasaran saat ini mengandung minyak nabati sebagai satu-satunya sumber lemak (Gianni et al. 2012). Novian (2019) telah melakukan penelitian tentang profil asam lemak pada produk formula yang beredar di Indonesia dan menyimpulkan terdapat empat jenis campuran minyak nabati yang digunakan sebagai sumber lemak pada produk formula yaitu minyak kelapa sawit, kedelai, kelapa, dan biji bunga matahari. Tabel 2 menunjukkan data kadar lemak dalam produk formula, jenis minyak nabati pada produk formula (Novian 2019) dan kadar lemak yang terdapat pada label kemasan produk formula.

Produk formula bayi mengandung kadar lemak yang lebih tinggi dibandingkan formula lanjutan. Perbedaan kandungan lemak ini disesuaikan dengan kebutuhan bayi. Produk formula dirancang agar mengandung komponen zat gizi yang dapat menyerupai kandungan gizi pada ASI. Komposisi ASI bersifat dinamis dan berubah seiring waktu sesuai dengan perubahan kebutuhan bayi yang sedang tumbuh (Martin et al. 2016; Delplanque et al. 2015), sedangkan untuk mendapatkan komposisi lemak pada produk formula agar dapat menyerupai komposisi lemak pada ASI perlu dilakukan variasi pada penggunaan minyak nabati sebagai sumber lemak (Delplanque et al. 2015). 
Berdasarkan Tabel 2 sebanyak 45-49\% minyak nabati yang digunakan sebagai sumber lemak pada produk formula yang beredar di Indonesia adalah minyak kelapa sawit. Beberapa minyak nabati memiliki komposisi yang spesifik misalnya minyak kelapa sawit yang memiliki kandungan asam lemak jenuh palmitat yang tinggi, sedangkan minyak kelapa mengandung asam lemak jenuh laurat dan miristat (Delplanque et al. 2015). ASI memiliki kandungan asam lemak jenuh palmitat yang tinggi, oleh karena itu agar dapat menyerupai komposisi ASI produk formula dirancang mengandung kaya akan asam lemak jenuh palmitat (Martin et al. 2016).

Kadar rata-rata lemak hasil penelitian Novian (2019) ini lebih rendah dari kadar rata-rata lemak yang tercantum pada label produk formula. Label kemasan produk formula tidak memberikan informasi mengenai jenis minyak nabati yang digunakan. Oleh karena itu, penentuan prediksi kadar 3-MCPDE dan GE dari produk formula menggunakan data kadar rata-rata lemak pada label kemasan, namun jenis dan persentase minyak nabati di dalam produk formula diambil dari data hasil penelitian Novian (2019).

Kadar 3-MCPDE dan GE dari minyak kelapa sawit, kedelai, kelapa dan biji bunga matahari

Data kadar 3-MCPDE dan GE disajikan dalam bentuk kisaran Lower Bound (LB) dan Upper Bound (UB). Pada LB, kadar 3-MCPDE dan GE pada sampel yang tidak terdeteksi diasumsikan sebagai 0 (nol) sedangkan untuk UB, kadar 3-MCPDE dan GE pada sampel yang tidak terdeteksi disamakan dengan nilai LoD-nya (FAO/WHO 2009). Kadar rata-rata 3-MCPDE pada minyak kelapa sawit tidak memenuhi batas persyaratan sebagai bahan pangan untuk produk formula dan makanan bayi dan anak usia 1-3 tahun. Batas maksimum 3-MCPDE sebagai bahan pangan untuk produk formula dan makanan bayi dan anak usia 1-3 tahun regulasi Uni Eropa adalah sebesar $750 \mu \mathrm{g} / \mathrm{kg}$ (EC 2020), sedangkan kadar rata-rata 3-MCPDE minyak kelapa sawit yang didapatkan adalah $2003.70 \mu \mathrm{g} / \mathrm{kg}$. Kadar rata-rata minyak kedelai, kelapa dan biji bunga matahari memenuhi persyaratan yang ditetapkan oleh regulasi Uni Eropa dengan nilai rata-rata secara berturutturut adalah 188.05-201.05; 573.13-581.93 dan 287.63 $\mu \mathrm{g} / \mathrm{kg}$.

Uni Eropa menetapkan batas maksimum GE untuk kategori bahan pangan yang digunakan untuk produk formula dan makanan bayi dan anak usia 1-3 tahun adalah $500 \mu \mathrm{g} / \mathrm{kg}$ (EC 2020). Kadar rata-rata GE pada minyak kedelai dan biji bunga matahari memenuhi persyaratan regulasi Uni Eropa untuk kategori tersebut. Kadar rata-rata GE pada minyak kedelai dan biji bunga matahari yang didapatkan dari hasil pengujian ini adalah sebesar 214.96 dan $211.55 \mu \mathrm{g} / \mathrm{kg}$. Minyak kelapa dan minyak kelapa sawit tidak memenuhi batas maksimum persyaratan yang ditetapkan oleh Uni Eropa untuk kategori bahan pangan yang digunakan pada produk formula dan makanan bayi dan anak usia 1-3 tahun. Kadar rata-rata GE pada minyak kelapa adalah sebesar $707.26 \mu \mathrm{g} / \mathrm{kg}$, sedangkan pada minyak kelapa sawit cukup tinggi yaitu sebesar $7393.90 \mu \mathrm{g} / \mathrm{kg}$. Nilai ratarata, median dan P95 3-MCPDE dan GE nabati kelapa sawit, kedelai, kelapa dan biji bunga matahari dapat dilihat pada Gambar 1.

Tabel 2. Kadar lemak dalam produk formula dan jenis minyak nabati penyusun lemak

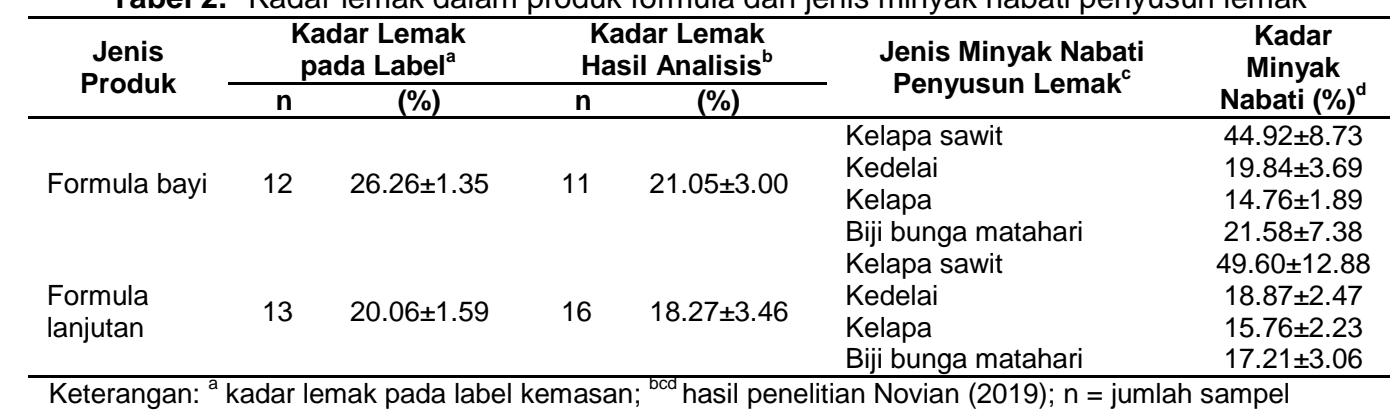

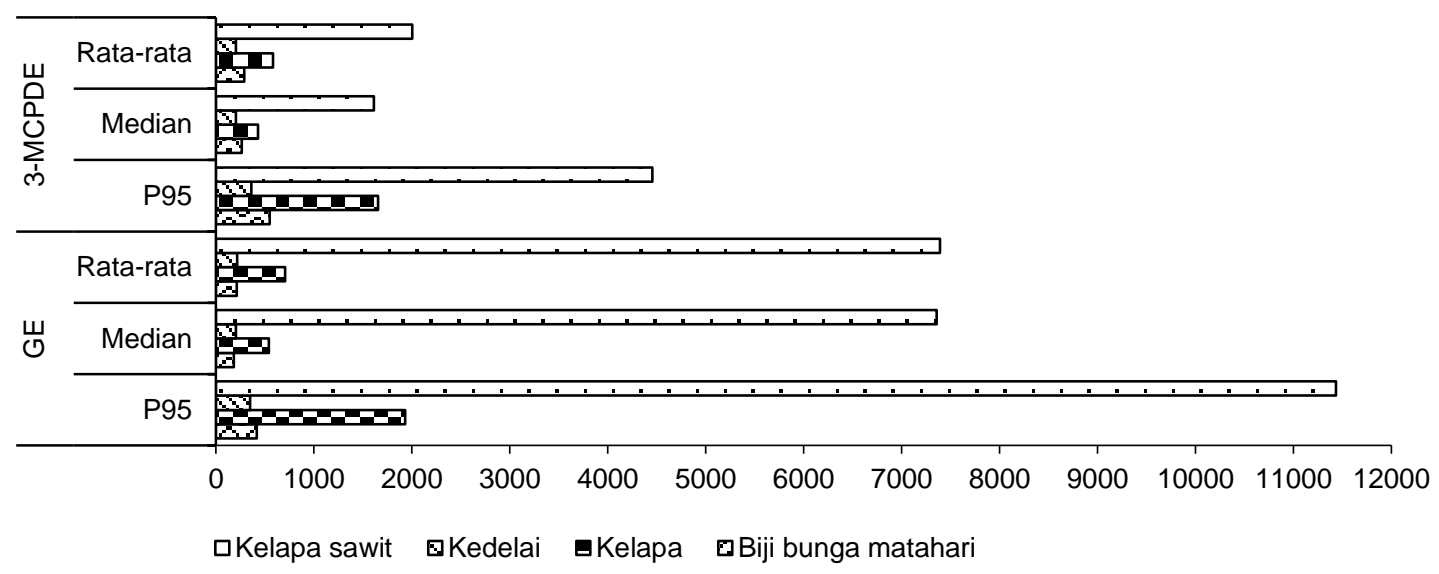

Gambar 1. Kadar 3-MCPDE dan GE pada berbagai minyak nabati ( $\mu \mathrm{g} / \mathrm{kg}$ ) (diambil nilai upperbound) 


\section{Penentuan prediksi kadar 3-MCPDE dan GE dari produk formula secara probabilistik}

Hasil penghitungan dengan simulasi Monte Carlo menggunakan aplikasi@RISK didapatkan nilai rata-rata prediksi kadar 3-MCPDE dan GE dari produk formula tidak memenuhi persyaratan batas maksimum regulasi Uni Eropa. Uni Eropa menetapkan batas maksimum kadar 3-MCPDE dan GE pada produk formula dan makanan untuk kebutuhan medis khusus dalam bentuk bubuk adalah sebesar 125 dan $50 \mu \mathrm{g} / \mathrm{kg}$ (EU 2020). Hasil penelitian menunjukkan rata-rata prediksi kadar 3MCPDE dan GE dari produk formula berkisar antara $213.60-285.65$ dan $772.89-922.73 \mu \mathrm{g} / \mathrm{kg}$ dengan nilai P95 sebesar 472.77-595.99 dan 1367.91-1544.47 $\mu \mathrm{g} / \mathrm{kg}$. Nilai rata-rata, median dan P95 prediksi kadar 3MCPDE dan GE selengkapnya dapat dilihat pada Gambar 2.

Nilai rata-rata prediksi kadar 3-MCPDE dari formula bayi dan formula lanjutan hasil penelitian ini masih lebih lebih rendah dari data kadar 3-MCPDE hasil penelitian Leigh dan MacMahon (2017), namun lebih tinggi dari data yang dilaporkan oleh Arisetto et al. (2017). Leigh dan MacMahon (2017) melakukan analisis terhadap 98 sampel formula bayi di Amerika Serikat. Sampel formula bayi yang digunakan pada penelitian ini diproduksi oleh tujuh produsen yang berbeda dan lima di antaranya menggunakan minyak kelapa sawit sebagai sumber lemak. Kadar 3-MCPDE dan GE pada 98 sampel formula bayi tersebut berkisar antara 21 sampai $920 \mu \mathrm{g} / \mathrm{kg}$ dan mulai dari <LOQ (10 $\mu \mathrm{g} / \mathrm{kg}$ ) sampai dengan $400 \mu \mathrm{g} / \mathrm{kg}$. Kandungan 3MCPDE dan GE paling tinggi didapatkan dari produsen produk formula yang menggunakan minyak kelapa sawit, namun kadar 3-MCPDE dan GE terendah juga berasal dari produsen yang menggunakan minyak kelapa sawit. Kadar 3-MCPDE dan GE yang rendah ini disebabkan karena produsen produk formula tersebut menggunakan minyak kelapa sawit yang telah melakukan beberapa mitigasi dalam proses permurniannya. Hal ini menunjukkan bahwa efektivitas strategi mitigasi pada ingredient (bahan pangan) dapat menurunkan kadar 3-MCPDE dan GE pada produk akhir.
Arisetto et al. (2017) melakukan sampling dan pengujian terhadap 40 sampel formula bayi dan formula lanjutan yang beredar di Brazil dan mendapatkan hasil kadar 3-MCPDE berada pada rentang tidak terdeteksi sampai $600 \mu \mathrm{g} / \mathrm{kg}$ dengan nilai rata-rata $150 \mu \mathrm{g} / \mathrm{kg}$ dan nilai P95 sebesar $350 \mu \mathrm{g} / \mathrm{kg}$ (LOD \& LOQ $=80$ dan 160 $\mu \mathrm{g} / \mathrm{kg}$ ). Kadar GE pada pengujian ini berada pada rentang tidak terdeteksi sampai dengan $750 \mu \mathrm{g} / \mathrm{kg}$ dengan kadar rata-rata $220 \mu \mathrm{g} / \mathrm{kg}$ dan P95 $630 \mu \mathrm{g} / \mathrm{kg}$ (LOD \& LOQ = 100 dan $200 \mu \mathrm{g} / \mathrm{kg}$ ). Hasil pengujian 3MCPDE dan GE pada formula bayi dengan kadar yang lebih rendah dilaporkan oleh Becalski et al. (2015). Kadar 3-MCPDE berkisar antara $<6 \mu \mathrm{g} / \mathrm{kg}$ sampai dengan $89 \mu \mathrm{g} / \mathrm{kg}$ dan untuk GE berkisar antara $<10$ sampai dengan $70 \mu \mathrm{g} / \mathrm{kg}$ pada formula bayi di Kanada dalam tiga bentuk yang berbeda (konsentrat, siap pakai dan bubuk). EFSA (2016) melaporkan kadar rata-rata 3MCPDE dan GE pada formula bayi adalah 108 dan 87 $\mu \mathrm{g} / \mathrm{kg}$. Zelinkova et al. (2009) mendapatkan hasil pengujian 3-MCPDE pada formula bayi berkisar 62 sampai $588 \mu \mathrm{g} / \mathrm{kg}$.

Nilai rata-rata prediksi kadar GE berada pada level yang tinggi apabila dibandingkan dengan hasil penelitian pada beberapa publikasi ilmiah lainnya. Hal ini disebabkan tingginya kadar GE dari minyak kelapa sawit yang digunakan datanya pada penghitungan ini yaitu dengan nilai rata-rata $7393 \mu \mathrm{g} / \mathrm{kg}$, selain itu persentase minyak kelapa sawit dalam produk formula yang relatif tinggi berkisar antara $44-49 \%$ juga memberikan kontribusi yang signifikan. Faktor-faktor yang memberikan kontribusi terhadap tingginya nilai prediksi kadar GE pada produk formula dapat dilihat dengan menggunakan sensitivity analysis pada aplikasi @ RISK 7.6 dengan spearman correlation coefficient. Secara umum hasil dari sensitivity analysis menunjukkan tiga faktor terbesar yang memberikan kontribusi terhadap tingginya nilai prediksi kadar GE pada produk formula yaitu: kadar GE minyak kelapa sawit dengan nilai koefisien sebesar 0.86 , persentase minyak kelapa sawit dalam produk formula dengan nilai koefisien sebesar 0.44 dan kadar lemak dengan nilai koefisien sebesar 0.13 . Hasil sensitivity analysis prediksi kadar GE pada formula bayi dapat dilihat pada Gambar 3.

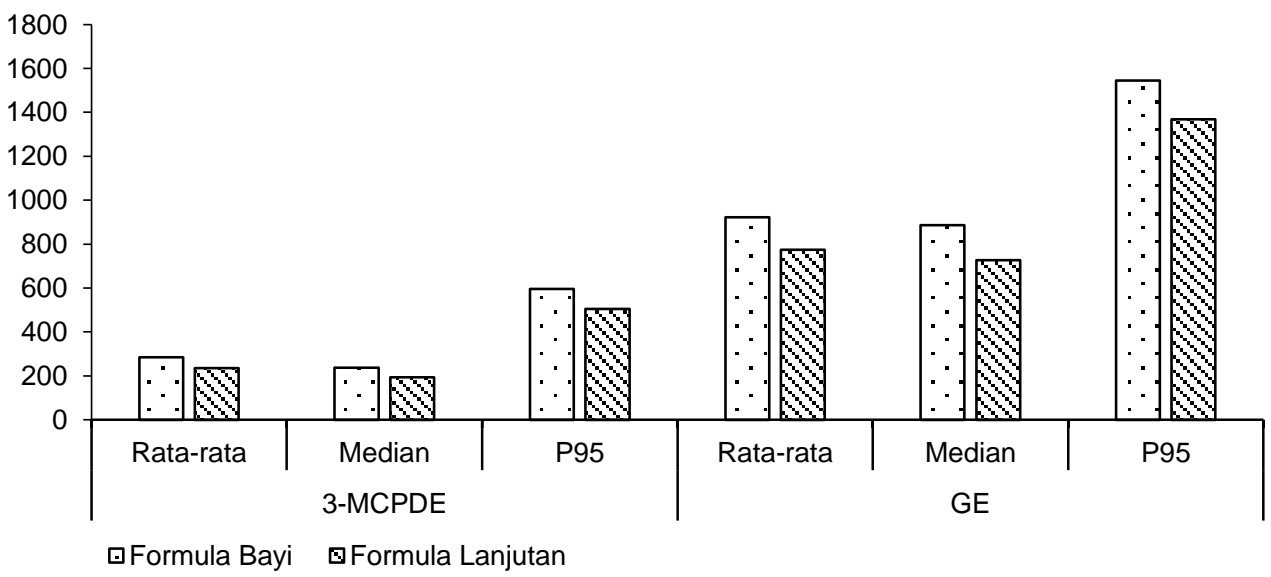

Gambar 2. Prediksi kadar 3-MCPDE dan GE ( $\mu \mathrm{g} / \mathrm{kg}$ ) dari produk formula (diambil nilai upper bound) 


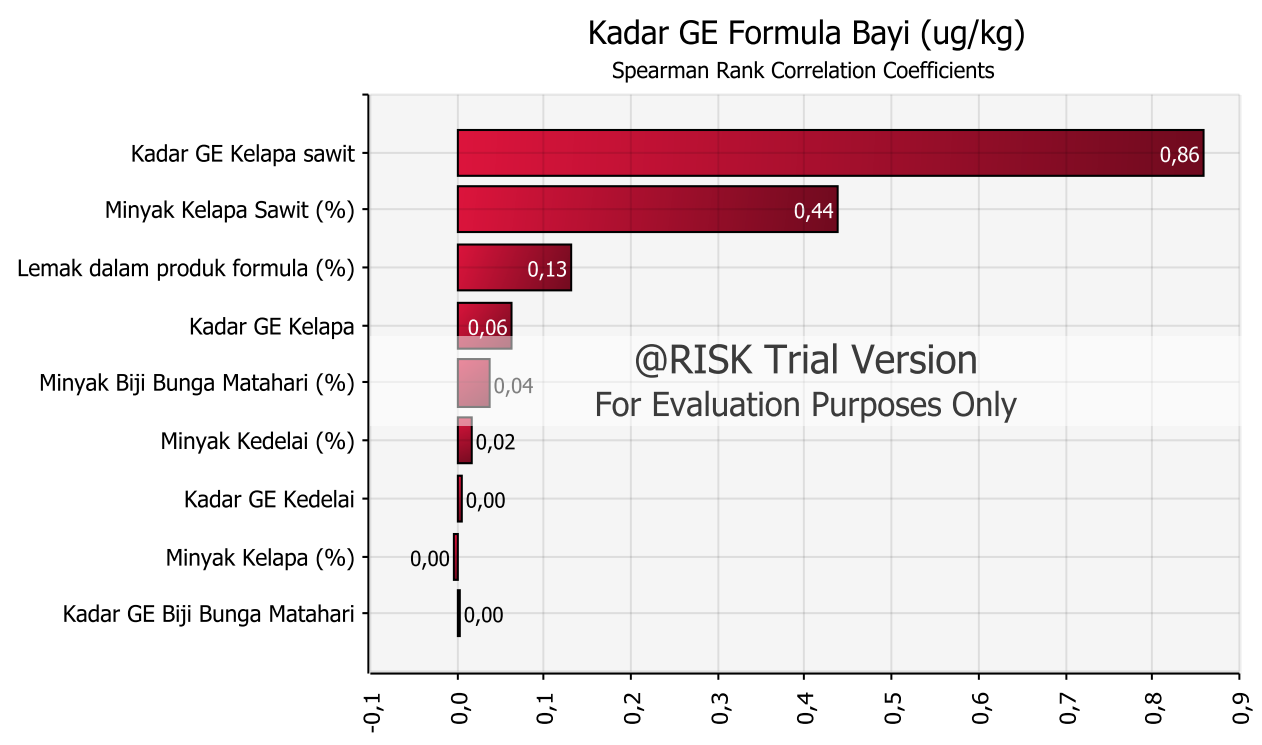

Gambar 3. Hasil sensitivity analysis prediksi kadar GE dari formula bayi

\section{Pengumpulan dan pengolahan data konsumsi dan berat badan bayi secara probabilsitik}

Pada penelitian ini data konsumsi dan berat badan bayi didapatkan dari data survei konsumsi makanan individu (Kemenkes 2014) dan takaran saji dari label kemasan. Nilai rata-rata konsumsi formula bayi dan formula lanjutan berdasarkan data SKMI adalah 38.99 dan $63.53 \mathrm{~g} /$ hari, sedangkan berdasarkan konsumsi takaran saji adalah 109.38 dan $124.50 \mathrm{~g} /$ hari. Berat badan rata-rata bayi kelompok usia 0-6 bulan dan 6-12 bulan berdasarkan data SKMI adalah 5.07 dan $8.99 \mathrm{~kg}$. Berat badan rata-rata bayi usia 0-6 bulan ini lebih rendah dari berat badan anjuran pemerintah yang diatur dalam Peraturan Menteri Kesehatan No 28 Tahun 2019 (Kemenkes 2019) tentang Angka Kecukupan Gizi yang Dianjurkan untuk Masyarakat Indonesia. Berat badan rata-rata bayi usia 0-6 bulan dan 6-12 bulan menurut anjuran pemerintah adalah 6 dan $9 \mathrm{~kg}$. Rincian konsumsi produk formula dan berat badan bayi di Indonesia disajikan pada Tabel 3 .

Tabel 3. Konsumsi produk formula dan berat badan bayi

\begin{tabular}{lcccccc}
\hline \multirow{2}{*}{$\begin{array}{c}\text { Kelompok } \\
\text { Usia }\end{array}$} & \multicolumn{2}{c}{$\begin{array}{c}\text { Konsumsi } \\
\text { SKMI }\end{array}$} & \multicolumn{2}{c}{$\begin{array}{c}\text { Konsumsi } \\
\text { Takaran Saji }\end{array}$} & \multicolumn{2}{c}{$\begin{array}{c}\text { Berat Badan } \\
\text { Bayi }\end{array}$} \\
\cline { 2 - 7 } & $\mathbf{n}$ & $\mathbf{( g / h a r i )}$ & $\mathbf{n}$ & $\mathbf{( g / h a r i )}$ & $\mathbf{n}$ & $\mathbf{( k g )}$ \\
\hline 0-6 bulan & & & & & & \\
Rata-rata & \multirow{2}{*}{156} & 38.99 & 12 & 109.38 & 156 & 5.07 \\
Median & 30.91 & & 110.54 & & 4.89 \\
P95 & & 97.88 & & 118.81 & & 7.74 \\
\hline 6-12 bulan & & & & & & \\
Rata-rata & \multirow{2}{*}{197} & 63.53 & 13 & 124.50 & 197 & 8.99 \\
Median & & 56.93 & & 124.50 & & 8.93 \\
P95 & & 136.22 & & 142.05 & & 11.18 \\
\hline
\end{tabular}

Keterangan: $\mathrm{n}=$ jumlah sampel; Konsumsi takaran saji merupakan anjuran takaran saji dari pelaku usaha yang dicantumkan pada label kemasan produk formula

Kajian paparan 3-MCPDE dan GE dari produk formula pada bayi secara probabilistik

Nilai rata-rata paparan 3-MCPDE dari produk formula menggunakan konsumsi SKMI berkisar antara 1.53-2.40 dengan nilai P95 sebesar 4.31-7.46 $\mu \mathrm{g} / \mathrm{kgBB} /$ hari, sedangkan menggunakan data konsumsi takaran saji adalah 3.31-6.68 dengan nilai P95 sebesar 7.19$15.03 \mu \mathrm{g} / \mathrm{kgBB} /$ hari. Nilai rata-rata paparan 3-MCPDE dari produk formula pada penelitian ini lebih rendah dibandingkan dengan nilai rata-rata yang diperoleh Spungen et al. (2018). Spungen et al. (2018) melakukan kajian paparan 3-MCPDE dan GE pada bayi usia 0-6 bulan yang mengonsumsi formula bayi di Amerika Serikat dan mendapatkan nilai paparan 3-MCPDE berkisar antara 7-10 $\mu \mathrm{g} / \mathrm{kgBB} / \mathrm{hari}$. Arisetto et al. (2017) melakukan kajian paparan 3-MCPDE pada bayi kelompok usia 0-5 bulan dan 6-11 bulan yang mengonsumsi produk formula di Brazil. Hasil kajian menunjukkan nilai rata-rata paparan 3-MCPDE adalah 2.49 dan $1.05 \mu \mathrm{g} / \mathrm{kgBB} /$ hari dengan nilai P95 sebesar 5.81 dan $2.45 \mu \mathrm{g} / \mathrm{kgBB} /$ hari untuk kelompok usia 0-5 bulan dan 6-11 bulan.

Nilai rata-rata dan nilai P95 paparan 3-MCPDE dari produk formula pada penelitian ini lebih rendah dibandingkan dengan nilai yang diperoleh JECFA (2017) namun lebih tinggi dari nilai paparan yang dilaporkan oleh EFSA (2016). JECFA (2017) melaporkan paparan 3-MCPDE pada bayi yang mengonsumsi produk formula dapat mencapai $10 \mu \mathrm{g} / \mathrm{kgBB} /$ hari dengan nilai P95 sebesar 15-21 $\mu \mathrm{g} / \mathrm{kgBB} /$ hari. EFSA (2016) melakukan kajian paparan pada kelompok bayi usia 1-4 bulan. Hasil kajian menunjukkan nilai rata-rata paparan 3-MCPDE adalah 2.4 dengan nilai P95 sebesar 3.2 $\mu \mathrm{g} / \mathrm{kgBB} /$ hari. Nilai paparan 3-MCPDE dan GE dari produk formula pada bayi di Indonesia dapat dilihat pada Tabel 4.

Nilai rata-rata paparan GE dari produk formula pada penelitian ini berada pada level yang tinggi yaitu 5.317.11 dengan nilai P95 sebesar 13.48-23.04 $\mu \mathrm{g} / \mathrm{kgBB} / \mathrm{hari}$ (konsumsi SKMI), sedangkan berdasarkan konsumsi takaran saji adalah 10.88-21.62 dengan nilai P95 sebesar 20.11-41.80 $\mu \mathrm{g} / \mathrm{kgBB} / \mathrm{hari}$. EFSA (2016) memperoleh nilai rata-rata paparan GE adalah 1.9 dengan nilai P95 sebesar $4.9 \mu \mathrm{g} / \mathrm{kgBB} /$ hari. JECFA (2017) mendapatkan 
nilai rata-rata paparan GE berkisar antara 0.1-3.6 dengan nilai P95 sebesar 0.3-4.9 $\mu \mathrm{g} / \mathrm{kgBB} / \mathrm{hari}$. Arisetto et al. (2017) melaporkan rata-rata paparan GE pada kelompok usia 0-5 bulan dan 6-11 bulan di Brazil adalah 3.65 dan $1.54 \mu \mathrm{g} / \mathrm{kgBB} / \mathrm{hari}$ dengan nilai P95 sebesar 10.46 dan $4.44 \mu \mathrm{g} / \mathrm{kgBB} / \mathrm{hari}$. Spungen et al. (2018) melaporkan paparan GE pada kelompok usia 0-6 bulan yang mengonsumsi formula bayi di Amerika serikat dengan nilai rata-rata sebesar $2 \mu \mathrm{g} / \mathrm{kgBB} / \mathrm{hari}$.

Tabel 4. Paparan 3-MCPDE dan GE dari produk formula pada bayi di Indonesia

\begin{tabular}{|c|c|c|c|c|}
\hline \multirow{3}{*}{$\begin{array}{c}\text { Kelompok } \\
\text { Usia }\end{array}$} & \multicolumn{4}{|c|}{ Nilai Paparan $(\mu \mathrm{g} / \mathrm{kgBB} / \mathrm{hari})$} \\
\hline & \multicolumn{2}{|c|}{ Data Konsumsi SKMI } & \multicolumn{2}{|c|}{ Konsumsi Takaran Saji } \\
\hline & a-MCPDE & ${ }^{a} \mathrm{GE}$ & a'3-MCPDE & ${ }^{\mathrm{a}} \mathrm{GE}$ \\
\hline \multicolumn{5}{|l|}{$0-6$ bulan } \\
\hline Rata-rata & $\begin{array}{c}2.37- \\
2.40\end{array}$ & $\begin{array}{l}7.70- \\
7.11\end{array}$ & $\begin{array}{l}6.67- \\
6.68\end{array}$ & $\begin{array}{l}21.62- \\
21.62\end{array}$ \\
\hline Median & $\begin{array}{l}1.49- \\
1.52\end{array}$ & $\begin{array}{l}5.21- \\
5.23\end{array}$ & $\begin{array}{l}5.41- \\
5.46\end{array}$ & $\begin{array}{c}19.50- \\
19.56\end{array}$ \\
\hline P95 & $\begin{array}{l}7.32- \\
7.46\end{array}$ & $\begin{array}{l}22.92- \\
23.04\end{array}$ & $\begin{array}{l}15.07- \\
15.03\end{array}$ & $\begin{array}{c}41.80- \\
41.80\end{array}$ \\
\hline \multicolumn{5}{|l|}{$6-12$ bulan } \\
\hline Rata-rata & $\begin{array}{l}1.53- \\
1.68\end{array}$ & $\begin{array}{l}5.54- \\
5.54\end{array}$ & $\begin{array}{l}3.31- \\
3.31\end{array}$ & $\begin{array}{l}10.88- \\
10.91\end{array}$ \\
\hline Median & $\begin{array}{l}1.08- \\
1.21\end{array}$ & $\begin{array}{c}4.35- \\
4.36\end{array}$ & $\begin{array}{c}2.68- \\
2.69\end{array}$ & $\begin{array}{l}10.05- \\
10.17\end{array}$ \\
\hline P95 & $\begin{array}{l}4.27- \\
4.64\end{array}$ & $\begin{array}{l}14.41- \\
14.41\end{array}$ & $\begin{array}{l}7.19- \\
7.19\end{array}$ & $\begin{array}{c}20.11- \\
20.39\end{array}$ \\
\hline
\end{tabular}

\section{Karakterisasi risiko 3-MCPDE dan GE dari produk formula pada bayi secara probabilistik}

Penilaian risiko 3-MCPDE diperoleh dengan membandingkan nilai paparan dengan nilai TDI (EFSA 2018) yaitu $2 \mu \mathrm{g} / \mathrm{kgBB} / \mathrm{hari}$. Nilai rata-rata persentase risiko 3MCPDE dari produk formula menggunakan data konsumsi SKMI dan takaran saji di atas $100 \%$ atau berada di tingkat yang berisiko terhadap kesehatan kecuali pada kelompok usia 6-12 berdasarkan data konsumsi SKMI dengan nilai rata-rata $76.98-84.34 \%$. Tabel 5 menyajikan data tingkat risiko 3-MCPDE dan GE dari produk formula.

Tabel 5. Tingkat risiko 3-MCPDE dan GE dari produk formula pada bayi di Indonesia

\begin{tabular}{|c|c|c|c|c|}
\hline \multirow{2}{*}{$\begin{array}{l}\text { Kelompok } \\
\text { Usia }\end{array}$} & \multicolumn{2}{|c|}{$\begin{array}{c}\text { Karakterisasi Risiko 3- } \\
\text { MCPDE (\%) }\end{array}$} & \multicolumn{2}{|c|}{$\begin{array}{c}\text { Karakterisasi Risiko } \\
\text { GE (MoE T25) }\end{array}$} \\
\hline & $\begin{array}{c}\text { Konsumsi } \\
\text { SKMI }\end{array}$ & $\begin{array}{c}\text { Konsumsi } \\
\text { Takaran } \\
\text { Saji }\end{array}$ & $\begin{array}{c}\text { Konsumsi } \\
\text { SKMI }\end{array}$ & $\begin{array}{c}\text { Konsumsi } \\
\text { Takaran } \\
\text { Saji }\end{array}$ \\
\hline \multicolumn{5}{|l|}{$0-6$ bulan } \\
\hline Rata-rata & $\begin{array}{l}118.58- \\
119.67\end{array}$ & $\begin{array}{l}334.18- \\
334.31\end{array}$ & $\begin{array}{c}1324- \\
1323\end{array}$ & $\begin{array}{l}471- \\
471\end{array}$ \\
\hline Median & $\begin{array}{c}74.74- \\
74.75\end{array}$ & $\begin{array}{l}269.79- \\
273.04\end{array}$ & $\begin{array}{c}1950- \\
1950\end{array}$ & $\begin{array}{c}522- \\
521\end{array}$ \\
\hline P95 & $\begin{array}{l}365.89- \\
375.13\end{array}$ & $\begin{array}{l}753.66- \\
751.80\end{array}$ & $\begin{array}{c}444- \\
442\end{array}$ & $\begin{array}{l}244- \\
244\end{array}$ \\
\hline \multicolumn{5}{|l|}{$6-12$ bulan } \\
\hline Rata-rata & $\begin{array}{l}76.98- \\
84.34\end{array}$ & $\begin{array}{l}165.31- \\
166.39\end{array}$ & $\begin{array}{c}1838- \\
1832\end{array}$ & $\begin{array}{l}936- \\
934\end{array}$ \\
\hline Median & $\begin{array}{l}53.84- \\
60.98\end{array}$ & $\begin{array}{c}134.61- \\
135.16\end{array}$ & $\begin{array}{l}2342- \\
2336\end{array}$ & $\begin{array}{l}1014- \\
1002\end{array}$ \\
\hline P95 & $\begin{array}{l}213.70- \\
224.81\end{array}$ & $\begin{array}{l}365.4- \\
366.09\end{array}$ & $\begin{array}{l}707- \\
703\end{array}$ & $\begin{array}{l}507- \\
500\end{array}$ \\
\hline
\end{tabular}

Keterangan: ${ }^{2}$ disajikan dalam kisaran Lower Bound - Upper Bound; Nilai TDI 3-MCPDE adalah $2 \mu \mathrm{g} / \mathrm{kgBB} / \mathrm{hari}$ (EFSA 2018) dan nilai T25 GE adalah $10.2 \mathrm{mg} / \mathrm{kgBB} /$ hari pada hewan percobaan tikus jantan (EFSA 2016)
Penilaian risiko GE dari produk formula dilakukan dengan menggunakan pendekatan Margin of Exposure (MoE) T25 (EFSA 2016). Nilai T25 untuk GE adalah $10.2 \mathrm{mg} / \mathrm{kgBB} / \mathrm{hari}$ (EFSA 2016). EFSA (2016) menetapkan nilai MoE T25 GE diatas 25.000 sebagai batas risiko rendah terhadap kesehatan. Nilai rata-rata $\mathrm{MoE}$ GE yang didapatkan pada penelitian ini masih belum memenuhi batas risiko rendah nilai $\mathrm{MoE}$ yang ditetapkan oleh EFSA (2016) yaitu berkisar antara 1838471.

\section{KESIMPULAN}

Hasil penelitian menunjukkan nilai rata-rata prediksi kadar 3-MCPDE dan GE dari produk formula berkisar antara $213.60-285.6573 \mu \mathrm{g} / \mathrm{kg}$ dan $772.89-922.73 \mu \mathrm{g} / \mathrm{kg}$. Nilai rata-rata ini masih belum memenuhi persyaratan batas maksimum kadar 3-MCPDE dan GE dari produk formula berdasarkan regulasi Uni Eropa. Nilai rata-rata paparan 3-MCPDE dan GE dari produk formula berdasarkan konsumsi SKMI adalah 1.53-2.40 dan 5.54-7.11 $\mu \mathrm{g} / \mathrm{kgBB} / \mathrm{hari}$, sedangkan berdasarkan konsumsi takaran saji adalah 3.31-6.68 dan 10.88-21.62 $\mu \mathrm{g} / \mathrm{kgBB} / \mathrm{hari}$. Hasil penilaian risiko 3-MCPDE dari produk formula berada di atas $100 \%$ (berisiko terhadap kesehatan) kecuali pada kelompok usia 6-12 bulan berdasarkan konsumsi SKMI. Penilaian risiko GE dengan pendekatan margin of exposure (MoE) T25 didapatkan nilai rata-rata MoE T25 masih berada di bawah 25.000 (MoE T25 $\geq 25.000$ sebagai batas risiko rendah GE terhadap kesehatan).

Keterbatasan pada penelitian ini adalah (1) Prediksi kadar 3-MCPDE dan GE pada produk formula ini menggunakan data 3-MCPDE dan GE dari minyak nabati yang tersedia di pasaran baik dengan izin edar MD maupun ML. Oleh karena itu untuk mendapatkan data paparan 3-MCPDE dan GE dari produk formula yang akurat perlu dilakukan kajian paparan dan risiko menggunakan data kadar 3-MCPDE dan GE dari produk formula hasil pengujian laboratorium. (2) Kajian paparan dan risiko 3-MCPDE dan GE pada bayi ini baru dilakukan satu jenis konsumsi. Kajian lebih lanjut perlu dilakukan pada produk pangan lainnya yang diduga mengandung cemaran 3-MCPDE dan GE agar didapatkan data paparan yang lebih lengkap.

\section{UCAPAN TERIMA KASIH}

Ucapan terima kasih penulis sampaikan kepada BPOM RI atas dukungannya dalam kegiatan penelitian ini.

\section{DAFTAR PUSTAKA}

Arisseto AP, Silva WC, Scaranelo GR, Vicente E. 2017. 3-MCPD and glycidyl esters in infant formulas from 
the Brazilian market: Occurrence and risk assessment. Food Cont 77(2): 76-81. DOI: 10.1016/ j. foodcont.2017.01.028.

Blanchard E, France LRD, Zhu P, Montaigu L De, Schuck P, Ouest A. 2013. Handbook of Food Powders. Woodhead Publishing Limited, Cambridge. ISBN: 9780857098672.

[BPOM] Badan Pengawas Obat dan Makanan RI. 2018. Laporan Tahunan Pusat Riset dan Kajian Obat dan Makanan 2018. BPOM RI, Jakarta.

Delplanque B, Gibson R, Koletzko B, Lapillonne A, Strandvik B. 2015. Lipid quality in infant nutrition: current knowledged. J Pediatr Gastroenterol Nutr 61(1): 8-17. DOI: 10.1097/MPG.0000000000000 818.

[EC] European Commission. 2020. Amending regulation amending Regulation (EC) No 1881/2006 as regards maximum levels of 3monochloropropanediol (3-MCPD), 3- MCPD fatty acid esters and glycidyl fatty acid esters in certain foods. EU J 310: 2-5.

[EFSA] European Food Safety Authority. 2016. Risks for human health related to the presence of 3-andmono-chloropropanediol (MCPD), and their fatty acid esters, and glycidyl fatty acid esters in food. EFSA J 14(5): 4426. DOI: 10.2903/j.efsa.2016. 4426.

[EFSA] European Food Safety Authority. 2018. Update of the risk assessment on 3-monochloropropane diol and its fatty acid esters. EFSA J 16(1): 5083. DOI: 10.2903/j.efsa.2018.5083.

[FAO/WHO] Food Agriculture Organization and World Health Organization. 2009. Principles and Methods for the Risk Assessment of Chemicals in Food. WHO Press, Geneva. ISBN: 9789241572408.

Gianni ML, Roggero P, Charlotte Baudry, Ligneul A, Morniroli D, Garbarino F, Ruyet PL, Mosca F. 2012. The influence of a formula supplemented with dairy lipids and plant oils on the erythrocyte membran omega-3 fatty acid profile in healthy fullterm infants: a double-blind randomized controlled trial. BMC Pediatrics 12: 164-171. DOI: 10.1186/1471-2431-12-164.

[IARC] International Agency for Research on Cancer. 2012. Monographs on the Evaluation of Carcinogenic Risks to Human. Vol 101. International Agency for Research on Cancer, Lyon. ISBN: 9789283213246.

[JECFA] Joint FAO/WHO Expert Committee on Food Additives. 2017. Evaluation of Certain Contaminants in Food. WHO Press, Geneva. ISBN: 978-92-4-069642-6.

[Kemenkes] Kementerian Kesehatan. 2019. Peraturan Pemerintah Republik Indonesia Nomor 28 Tahun 2019 tentang Angka Kecukupan Gizi yang dianjurkan untuk Masyarakat Indonesia. Kemenkes, Jakarta.
[Kemenkes] Kementerian Kesehatan. 2018. Buku Hasil Riset Kesehatan Dasar 2018. Lembaga Penerbitan Litbangkes, Jakarta. ISBN: 978-602-373-118-3.

[Kemenkes] Kementerian Kesehatan. 2014. Buku Studi Diet Total: Survei Konsumsi Makanan Individu Indonesia 2014. Lembaga Penerbitan Litbangkes, Jakarta. ISBN: 978-602-1099-31-5.

Leigh J, MacMahon S. 2017. Occurrence of 3-monochloropropanediol esters and glycidyl esters in commercial infant formulas in the United States. Food Addit Contam Part A Chem Anal Control Expo Risk Assess 34(3): 356-370. DOI: 10.1080/194400 49. 2016.1276304.

Luron IE, Blat S, Boudry G. 2010. Breast-v. formulafeeding: impacts on the digestive tract and immediate and long-term health effects. Nutr Res Rev 23(1): 23-36. DOI: 10.1017/S0954422410000 065.

MacMahon S, Begley TH, Diachenko GW. 2013. Occurrence of 3-MCPD and glycidyl esters in edible oils in the United States. Food Addit Contam: Part A. 30(12): 2081-2092. DOI: 10.1080/19440049. 2013. 840805.

Martin CR, Ling PR, Blackburn GL. 2016. Review of infant feeding: Key features of breast milk and infant formula. Nutrient 8(5): 1-11. DOI: 10.3390/ nu80 50279.

Novian R. 2019. Profil Komposisi Asam Lemak pada Produk Formula di Indonesia [Skripsi]. Bogor: Institut Pertanian Bogor.

Pudel F, Benecke P, Vosmann K, Matthäus B. 2016. 3MCPD- and glycidyl esters can be mitigated in vege-table oils by use of short path distillation. Eur J Lipid Sci Technol 118(3): 396-405. DOI: 10.1002/ ejlt. 201500095.

Ryan T. 2013. Sample Size Determination and Power. John Wiley, New Jersey. ISBN: 9781118439241. DOI: $10.1002 / 9781118439241$.

Spungen J, Macmahon S, Leigh J, Flannery B, Kim G, Chirtel S, Smegal D. 2018. Estimated U.S. infant exposures to 3-MCPD esters and glycidyl esters from consumption of infant formula. Food Addit Contam Part A Chem Anal Control Expo Risk Assess 35(6): 1085-1092. DOI: 10.1080/19440049. 2018.1459051.

Wohrlin F, Fry H, Lahrssen-Wiederholt M, PreissWeigert A. 2015. Occurrence of fatty acid esters of 3-MCPD, 2-MCPD and glycidol in infant formula. Food Addit Contam Part A 32: 1810-1822. DOI: 10.1080/19440049.2015.1071497.

Zelinkova Z, Dolezal M, Velisek J. 2009. Occurrence of 3-chloropropane-1, 2-diol fatty acid esters in infant and baby foods. Eur Food Res Technol 228: 571578. DOI: 10.1007/s00217-008-0965-0.

JMP-01-21-01-Naskah diterima untuk ditelaah pada 26 Agustus 2020. Revisi makalah disetujui untuk dipublikasi pada 31 Oktober 2020. Versi Online: http://journal.ipb.ac.id/index.php/jmpi 
